\title{
Impact of Intra-Operative Fluid Therapy on Short Term Outcomes in Patients Undergoing Advanced Laparoscopic Colorectal Operations Performed for Colorectal Cancer
}

\author{
Jyothi Avula ${ }^{1}$, Gigi Varghese ${ }^{2}$, Bijesh Yadav ${ }^{3}$, Tony Thomson Chandy ${ }^{4}$ \\ ${ }^{1}$ Department of Anaesthesia, CMC, Vellore, Tamilnadu, India. ${ }^{2}$ Department of Colorectal \\ Surgery, CMC, Vellore, Tamilnadu, India. ${ }^{3}$ Department of Biostatistics, CMC, Vellore, \\ Tamilnadu, India. ${ }^{4}$ Department of Anaesthesia, CMC, Vellore, Tamilnadu, India.
}

\section{ABSTRACT}

\section{BACKGROUND}

There has been a recent shift in the operative approach in advanced colorectal operations where in laparoscopy is being used as the preferred modality of intraabdominal access. Literature is not clear and there is no consensus with regards to the optimal intraoperative fluid requirements in these operations. Hence, we did a retrospective study of intraoperative fluid requirements for all laparoscopic advanced colorectal resection operations and looked at its impact on short term postoperative recovery.

\section{METHODS}

This is a retrospective analysis of all patients who have undergone advanced laparoscopic colorectal resections in colorectal surgical unit in a single tertiary care centre in south India from January 2014 to June 2017. Data was collected from prospectively maintained electronic inpatient and outpatient charts. The outcomes analysed were postoperative morbidity and length of postoperative hospital stay with respect to intra-operative rate of intravenous (IV) fluid administration.

\section{RESULTS}

There was a total of 201 laparoscopic advanced colorectal resections performed from January 2014 to June 2017. The median IV fluid rate was $5.2 \mathrm{ml} / \mathrm{Kg} / \mathrm{hr}$ (SD1.97). Seventy nine of 201 patients were documented to have morbidity based on Clavien-Dindo classification. Patients who received intraoperative IV fluids $</=5$ $\mathrm{ml} / \mathrm{Kg} / \mathrm{hr}$ were categorised into the restrictive fluid regimen group and patients who received $>5 \mathrm{ml} / \mathrm{Kg} / \mathrm{hr}$ were categorised into the liberal fluid regimen group. Out of the 79 patients with post-operative morbidity, there was a statistically significant difference between the restrictive fluid group 32/79 (40.5\%) and the liberal fluid group $47 / 79$ (59.5\%) with a p value of 0.03 .

\section{CONCLUSIONS}

Intra-operative liberal fluid management seems to be associated with increased postoperative morbidity in laparoscopic advanced colorectal resections.

\section{KEY WORDS}

Laparoscopy, Colorectal Surgery, Intraoperative Fluids, Postoperative Morbidity
Corresponding Author: Dr. Gigi Varghese Department of Colorectal Surgery, CMC, Vellore,

Tamilnadu, India.

E-mail: gigivargh@gmail.com

DOI: $10.14260 /$ jemds $/ 2020 / 7$

Financial or Other Competing Interests: None.

How to Cite This Article:

Avula J, Varghese G, Yadav B, et al. Impact of intra-operative fluid therapy on short term outcomes in patients undergoing advanced laparoscopic colorectal operations performed for colorectal cancer. J. Evolution Med. Dent. Sci. 2020;9(01):29-32, DOI:
Submission 12-11-2019,

Peer Review 21-12-2019,

Acceptance 28-12-2019,

Published 06-01-2020. 


\section{BACKGROUND}

Minimally invasive colorectal resections, especially advanced laparoscopic resections are gaining more popularity in the management of locally advanced colorectal cancer and are likely to be the preferred approach in the immediate future. Identifying factors that will hasten recovery and facilitate early discharge is of utmost significance. Intraoperative fluid administration is a key element in influencing short-term post-operative outcomes. Traditionally intraoperative fluid administration involved large volumes with rationale to replace fasting and third space loss along with maintaining hemodynamic parameters.

There is clearly a lack of consensus in the literature with regards to the rate of intraoperative fluid therapy as worse outcomes are reported in both restrictive and liberal fluid regimens.(1) Moreover lack of standard definitions for restrictive, moderate and liberal fluid therapy regimen intraoperatively and type of fluids used along with inconsistencies in definition of complications studied have ushered in a lot of confusion in the literature.(2) A lot of data has emerged recently on targeted or goal directed fluid therapy compared to restrictive or liberal fluid regimen with varied results though most data support goal directed fluid therapy.(3) There is also uncertainty with regards to use of goal directed fluid therapy in low risk patients undergoing laparoscopic surgery in the background of ERAS (Enhanced recovery after surgery).(4),(5) These regimens are not standardised and are mostly studied in open operations. There are many other studies which support restrictive fluid regimen than liberal fluid regimen.(6) With laparoscopy becoming the mainstay of management along with ERAS implementation, it is important to assess the effects of intraoperative fluid volumes on patient outcomes and recovery in advanced laparoscopic colorectal resection.(7) It also has to be noted that minimally invasive or advanced laparoscopic colorectal resections are different from open operations with respect to intraoperative blood loss and thermodynamics.

Objective of this study was to investigate the short-term post-operative outcomes and its association with intraoperative fluid volumes in laparoscopic colorectal resections for colorectal cancer.

\section{METHODS}

This is a retrospective analysis of patients diagnosed with locally advanced colorectal cancer who have undergone laparoscopic colorectal resections from January 2014 to June 2017 at a single tertiary care centre in South India. After approval from the institutional review board (CMC Vellore IRB Min No: 10824 (dated 23.08.2017), data was extracted from the prospectively maintained electronic outpatient and inpatient record via the clinical workstation developed by the in-house computerized hospital information processing system (CHIPS) and analysed. There was a total of 201 patients included in the study, 124 of whom were males and 77 were females. The mean average age was 50 years and the average duration of surgery was 5 hours. Data collected as part of the study were age, sex, body weight, body mass index (BMI), American Society of Anaesthesiologists (ASA) status, preoperative haemoglobin and creatinine, duration of surgery and volume of crystalloids and colloids infused intraoperatively. Post-operative outcomes looked at were morbidity based on Clavien-Dindo classification and length of postoperative hospital stay. The average median intraoperative IV fluid rate was calculated to be $5.2 \mathrm{ml} / \mathrm{Kg} / \mathrm{Hr}$ with a standard deviation of 1.97. Based on the average IV fluid rate, patients were categorised into those receiving less than or equal to $5 \mathrm{ml} / \mathrm{Kg} / \mathrm{hr}$ as restrictive fluid regimen group and those receiving more than $5 \mathrm{ml} / \mathrm{Kg} / \mathrm{hr}$ as the liberal fluid regimen group.

The primary outcome was postoperative morbidity, which was graded based on Clavien-Dindo classification. (15),(8) Secondary outcome variable was length of postoperative hospital stay in days. Standard anaesthetic management was followed, and routine monitoring was used in all patients. Intraoperative fluid management was individualised, and decisions were made as per the anaesthetist's discretion determined by vital parameters and duration of surgery.

\section{Inclusion \& Exclusion Criteria}

All patients who have undergone advanced laparoscopic operations for colorectal cancer as an upfront procedure or after neoadjuvant therapy from January 2014 to July 2017 were included in the study. Laparoscopic operations that were converted to open procedures due to various indications were excluded from the study. Patients who had incomplete documentation or ambiguous data were also excluded.

\section{Statistical Analysis}

Data was entered using EPIDATA software and screened for outliers and extreme values using Box-Cox plot and histogram (for the shape of the distribution). Summary statistics was used for reporting demographic and clinical characteristics. All categorical variables were reported using frequencies and percentages and continuous variables were expressed in terms of mean \pm SD. Student $t$-test was used to compare continuous variables with IV fluids and the categorical variables were compared using the chi-square test. Differences will be considered significant at $p<0.05$. All the statistical analysis was performed using SPSS 25.0.

\section{RESULTS}

Among the 201 patients who underwent advanced laparoscopic colorectal resections, 121 patients had an uneventful postoperative recovery. 80 patients were documented to have morbidity based on Clavien-Dindo classification (1 to 5). Two patients were excluded from the final analysis due to lack of documentation of operating time. The median intraoperative fluid for the study cohort was 5.2 $\mathrm{ml} / \mathrm{Kg} / \mathrm{hr}$ based on which the patients were categorized into either the restrictive group $(</=5 \mathrm{ml} / \mathrm{Kg} / \mathrm{hr})$ or the liberal group ( $>5 \mathrm{ml} / \mathrm{Kg} / \mathrm{hr}$ ). There were 95 patients in the restrictive IV fluid regimen group and 104 patients in the liberal IV fluid regimen group. $47.7 \%$ patients $(32 / 95)$ in the 
restrictive IV fluid group had postoperative morbidity compared to $52.3 \%(47 / 104)$ in the liberal IV fluid group, which was not statistically significant. The mean length of postoperative hospital stay for the study cohort was 8.63 days with a standard deviation of 7.51. There was no difference in postoperative length of hospital between the restrictive and the liberal group.

\begin{tabular}{|c|c|c|c|}
\hline $\begin{array}{c}\text { Characteristics and } \\
\text { Variables }\end{array}$ & $\begin{array}{c}\text { Total } \\
\text { Cohort }(n=201)\end{array}$ & $\begin{array}{c}\text { Restrictive Fluid } \\
\text { Group } \\
(</=5 \mathrm{ml} / \mathrm{Kg} / \mathrm{hr} .)\end{array}$ & $\begin{array}{c}\text { Liberal Fluid } \\
\text { Group (>5 } \\
\text { ml/Kg/hr.) }\end{array}$ \\
\hline Age (years, mean, SD) & $50.1(14.643)$ & $53.24(14.1)$ & $47.39(14.5)$ \\
\hline \multicolumn{4}{|c|}{$\operatorname{Sex}(n, \%)$} \\
\hline Male & $124(61.7)$ & $63(51.6 \%)$ & $59(48.4 \%)$ \\
\hline Female & $77(38.3)$ & $32(41.6 \%)$ & $45(58.4 \%)$ \\
\hline Weight (Kg, mean, SD) & $62.72(12.779)$ & $68.09(12.4)$ & $58(11.2)$ \\
\hline BMI $(\mathrm{Kg} / \mathrm{m} 2$, mean, SD) & $23.738(4.55)$ & $25.23(4.4)$ & $22.43(4.3)$ \\
\hline \multicolumn{4}{|l|}{ ASA (n, \%) } \\
\hline 1 & $91(45.3)$ & $38(41.8 \%)$ & $53(58.2 \%)$ \\
\hline 2 & $107(53.2)$ & $55(52.4 \%)$ & $50(47.6 \%)$ \\
\hline$>/=3$ & $3(1.5)$ & $2(66.7 \%)$ & $1(33.3 \%)$ \\
\hline \multicolumn{4}{|c|}{ Preoperative Lab Variables } \\
\hline $\mathrm{Hb}(\mathrm{gm} / \mathrm{L}$, mean, SD) & $11.8(1$. & $12.07(1.99)$ & $11.52(1.99)$ \\
\hline S. Creatinine (mmoles/L) & $0.85(0.41)$ & $0.84(0.25)$ & $0.87(0.52)$ \\
\hline \multicolumn{4}{|c|}{ Surgical variables (n, \%) } \\
\hline Lap rectal ope & $139(69.2)$ & $66(47.8 \%)$ & $72(52.2 \%)$ \\
\hline Lap colon operations & $62(30.8)$ & $29(47.5 \%)$ & $32(52.5 \%)$ \\
\hline $\begin{array}{c}\text { Duration of Surgery } \\
\text { (mean hrs, SD) }\end{array}$ & $5.09(1.34)$ & $5.24(1.3)$ & $4.97(1.42)$ \\
\hline \multicolumn{4}{|c|}{$\begin{array}{l}\text { Intra-Operative Fluids (ml, mean, SD) } \\
\end{array}$} \\
\hline Crystalloids & $1454.23(580.1)$ & $1182.1(433.2)$ & $1730.8(543.8)$ \\
\hline Colloids & $174.1(300.1)$ & $155.58(296.5)$ & $194.3(305.6)$ \\
\hline Total & $1637.76(631.83)$ & $1341.4(429.2)$ & $1940(617.8)$ \\
\hline Blood (n, \%) & $8(0.4 \%)$ & $2(25 \%)$ & $6(75 \%)$ \\
\hline $\begin{array}{l}\text { Length of postoperative } \\
\text { hospital stay } \\
\text { (days, mean, SD) }\end{array}$ & $8.63(7.512)$ & $9.19(8.8)$ & $8.15(6.1)$ \\
\hline
\end{tabular}

\begin{tabular}{|c|c|c|c|}
\hline Outcome Variables & $\begin{array}{c}\text { Restrictive Fluid } \\
\text { Group (</=5 } \\
\text { ml/Kg/hr.) }\end{array}$ & $\begin{array}{c}\text { Liberal Fluid } \\
\text { Group } \\
(>\mathbf{5 ~ m l / K g / h r . )}\end{array}$ & $\mathbf{p}$ \\
\hline Postoperative morbidity (n, \%) & $63(52.5 \%)$ & $57(47.5 \%)$ & 0.09 \\
\hline No & $32(40.5 \%)$ & $47(59.5 \%)$ & 0.03 \\
\hline Yes (Clavien Dindo grade 1-5) & $9.19(8.803)$ & $8.15(6.138)$ & 0.33 \\
\hline $\begin{array}{c}\text { Length of postoperative hospital } \\
\text { stay (days, mean, SD) }\end{array}$ & Table 2. Patient Outcomes and IV Fluid Rates \\
\hline \multicolumn{2}{|c}{} \\
\hline
\end{tabular}

Among the 79 patients who had postoperative morbidity based on Clavien-Dindo classification, there was an increased number of patients with morbidity in the liberal IV fluid group $59.5 \%$ as compared to $40.5 \%$ ( $p$ value 0.03 ) in the restrictive group. This difference was found to be statistically significant.

\section{DISCUSSION}

The results of this study suggest that postoperative morbidity as calculated by Clavien Dindo grading in the liberal fluid regimen group ( $>5 \mathrm{ml} / \mathrm{Kg} / \mathrm{hr}$ ) is worse than that of restrictive fluid regimen group $(</=5 \mathrm{ml} / \mathrm{Kg} / \mathrm{hr})$ in patients undergoing Laparoscopic advanced colorectal resections. Literature is divided in its recommendations for optimal fluid therapy regimen during colorectal resection operations. Most intraoperative fluid therapy regimens are studied in the open colorectal operations and have been extrapolated to laparoscopic colorectal resections. Intraoperative fluid therapy needs to be tailored to the unique setting of advanced laparoscopic colorectal operations and optimized as per the benefits of laparoscopic resections in terms of lesser blood and fluid loss and better temperature control.(9),(10) Few studies done in laparoscopic surgeries show that in minor to moderate level procedures, liberal fluid administration improves recovery and shortens hospital stay as reported by Kathrine et al(11) and another study which looked at elective laparoscopic colorectal surgeries has suggested that goal directed fluid therapy during the operation has comparable outcomes to that of liberal fluid therapy in the context of enhanced recovery after surgery.(12) Whereas many other studies have shown that restrictive or zero balance approach decreases postoperative morbidity and length of hospital stay.(13),(14),(2) There are other studies, which show worse outcomes both with high fluid volume regimen and low fluid volume regimen group.(15),(3) The recent 'RELIEF' trial has shown that restrictive fluid regimen was not associated with higher rate of disability free survival, decreased morbidity and length of hospital stay but was associated with a higher rate of acute kidney injury.(16) They concluded that modestly liberal administration of fluid is safer than a restrictive regimen. A recent population based study has shown adverse outcomes with extremes of both liberal and restrictive fluid therapy, highlighting the importance of a balanced approach to peri -operative fluid management.(17),(1) There is evidence in the literature of increased incidence of acute kidney injury following extremes of restrictive and liberal fluid management in abdominal surgeries.(18),(3),(19)

Due to the heterogeneity of various studies, we still lack a universal definition of restrictive, liberal and moderately liberal fluid regimens. Hence these results from most studies cannot be extrapolated to specific settings especially in major laparoscopic colorectal resection operations. In our study, although there were no significant differences noted in the overall cohort of patients among the restrictive versus the liberal fluid group, there was statistically significant difference noted in a cohort of patients with varying grades of postoperative morbidity. Also, there was no difference in the length of postoperative hospital stay. This may be due to private and insured patients opting to stay in the hospital until suture removal, irrespective of fulfilling criteria for discharge.

The main strengths of this study is the fact that the impact of intraoperative fluid therapy was looked at in a specific group of advanced laparoscopic colorectal operations in a single center. Studies looking at intraoperative IV fluid regimen in advanced laparoscopic colorectal operations are sparse and that makes this study relevant. The retrospective nature of this study is a major limitation. More prospective randomized controlled trials may help in unravelling the impact of intraoperative fluid management on outcomes of major laparoscopic operations including comparison of postoperative weight gain and renal parameters.

\section{CONCLUSIONS}

Intraoperative liberal fluid therapy is associated with significantly increased postoperative morbidity as compared to restrictive fluid management in advanced laparoscopic colorectal operations. 


\section{REFERENCES}

[1] Varadhan KK, Lobo DN. A meta-analysis of randomised controlled trials of intravenous fluid therapy in major elective open abdominal surgery: getting the balance right. Proc Nutr Soc 2010;69(4):488-98.

[2] Doherty M, Buggy DJ. Intraoperative fluids: how much is too much? Br J Anaesth 2012;109(1):69-79.

[3] Shin CH, Long DR, McLean D, et al. Effects of intraoperative fluid management on postoperative outcomes: a hospital registry study. Ann Surg 2018;267(6):1084-92.

[4] Miller TE, Thacker JK, White WD, et al. Reduced length of hospital stay in colorectal surgery after implementation of an enhanced recovery protocol. Anesth Analg 2014;118(5):1052-61.

[5] Bennett-Guerrero E. Hemodynamic goal-directed therapy in high-risk surgical patients. JAMA 2014;311(21):2177-8.

[6] Joshi GP. Intraoperative fluid restriction improves outcome after major elective gastrointestinal surgery. Anesth Analg 2005;101(2):601-5.

[7] Rawlinson A, Kang P, Evans J, et al. A systematic review of enhanced recovery protocols in colorectal surgery. Ann R Coll Surg Engl 2011;93(8):583-8.

[8] Dindo D, Demartines N, Clavien PA. Classification of surgical complications: a new proposal with evaluation in a cohort of 6336 patients and results of a survey. Ann Surg 2004;240(2):205-13.

[9] Grocott MP, Mythen MG, Gan TJ. Perioperative fluid management and clinical outcomes in adults. Anesth Analg 2005;100(4):1093-106.

[10] Han JW, Oh AY, Seo KS, et al. Comparison of intraoperative basal fluid requirements in distal pancreatectomy: laparotomy vs. laparoscopy. Medicine (Baltimore) 2017;96(47):8763.
[11] Holte K, Klarskov B, Christensen DS, et al. Liberal versus restrictive fluid administration to improve recovery after laparoscopic cholecystectomy: a randomized, doubleblind study. Ann Surg 2004;240(5):892-9.

[12] Gómez-Izquierdo JC, Trainito A, Mirzakandov D, et al. Goal-directed fluid therapy does not reduce primary postoperative ileus after elective laparoscopic colorectal surgery: a randomized controlled trial. Anesthesiology 2017;127(1):36-49.

[13] Aga Z, Machina M, McCluskey SA. Greater intravenous fluid volumes are associated with prolonged recovery after colorectal surgery: a retrospective cohort study. $\mathrm{Br}$ J Anaesth 2016;116(6):804-10.

[14] Voldby AW, Brandstrup B. Fluid therapy in the perioperative setting-a clinical review. J Intensive Care 2016;4(1):27.

[15] Thacker JKM, Mountford WK, Ernst FR, et al. Perioperative fluid utilization variability and association with outcomes: considerations for enhanced recovery efforts in sample us surgical populations. Ann Surg 2016;263(3):502-10.

[16] REstrictive versus lib eral fluid therapy in major abdominal surgery - Clinical Trials.gov [cited 2018 Nov 18]. https://clinicaltrials.gov/ct2/show/NCT02073162

[17] Regenbogen SE, Shah NJ, Collins SD, et al. Populationbased assessment of intraoperative fluid administration practices across three surgical specialties. Ann Surg 2017;265(5):930-40.

[18] Myles PS, McIlroy DR, Bellomo R, et al. Importance of intraoperative oliguria during major abdominal surgery: findings of the restrictive versus liberal fluid therapy in major abdominal surgery trial. $\mathrm{Br} \mathrm{J}$ Anaesth 2019;122(6):726-33.

[19] Goren 0, Matot I. Perioperative acute kidney injury. Br J Anaesth 2015;(115 Suppl 2):ii3-ii14. 